\title{
ALTERAÇÃO DO CAMPO VISUAL EM FUNÇÃO DO USO DE CABINAS EM TRATORES AGRÍCOLAS
}

\author{
JOSÉ F. SCHLOSSER ${ }^{1}$, ARNO DALLMEYER ${ }^{2}$, HENRIQUE DEBIASI ${ }^{3}$, \\ MAURO T. MENEGAS ${ }^{4}$, GUSTAVO H. NIETIEDT ${ }^{5}$
}

\begin{abstract}
RESUMO: Com o objetivo de avaliar a alteração do campo visual de um trator, ocasionada pela instalação de uma cabina, foram determinadas as áreas de visibilidade nula em função da presença ou não da mesma, para cada campo visual. Os procedimentos adotados basearam-se na norma ISO 5721-1981 - Agricultural tractors - Operator's field of vision. A cabina aumentou em 34,42\% a área de visibilidade nula. A relação área de projeção do trator/área total sombreada foi de 0,075 para o trator sem cabina, e 0,057 para o trator com cabina, indicando as melhores condições de visibilidade do primeiro em relação ao segundo. No que se refere aos campos visuais, a maior redução ocorreu no campo visual dos olhos e no obtido com o movimento da cabeça, em função dos suportes da cabina e da estrutura de proteção contra o capotamento. A cabina diminui o campo de visão do operador, e adequações no projeto da estrutura avaliada são necessárias para melhorar as condições de visibilidade.
\end{abstract}

PALAVRAS-CHAVE: campo visual, tratores agrícolas, ergonomia.

\section{ALTERATION OF THE VISUAL FIELD IN FUNCTION OF THE USE OF CABINS IN AGRICULTURAL TRACTORS}

\begin{abstract}
Aiming to evaluate the alteration of the visual field of a tractor occasioned by the installation of a cabin were determined the null visibility areas due to the presence or not of this structure, for each visual field. The procedures adopted were based on ISO 5721-1981 Agricultural tractors - Operator's field of vision. The cabin increased in $34,42 \%$ the area of null visibility. The relationship projection area of tractor/total shadowed area was 0,075 to the tractor without a cabin, and 0,057 for the tractor with cabin, indicating the best conditions of visibility of the first in relation to the second. With respect to the visual area, the largest reduction happened in the eyes visual field and in the obtained with the head movement in function of the cabin supports and the rollover protection structure. The cabin decreases the operator's area of vision, and adjustments in the project of the structure evaluated are necessary to improve the visibility conditions.
\end{abstract}

KEYWORDS: visual field, agricultural tractors, ergonomics.

\section{INTRODUÇÃO}

A introdução de modernas máquinas para realização de tarefas que antes eram realizadas manualmente motivou a organização do trabalho, entretanto expõe os operadores a riscos de acidentes provocados pela falta de condições mínimas de segurança (LIMA et al., 2004). Embora os projetos de tratores agrícolas tenham evoluído consideravelmente, ainda não há o mesmo nível de

\footnotetext{
${ }^{1}$ Doutor, Professor Titular, Departamento de Engenharia Rural, UFSM,, Santa Maria - RS, Fone: (0XX55) 3220.8175; josefernandoschlosser@gmail.com.

${ }^{2}$ Doutor, Professor Voluntário, Departamento de Engenharia Mecânica, UFSM, Santa Maria - RS, Fone: (0XX55) 3220.8158; arno@agritoursbrasil.com.br.

${ }^{3}$ Doutor, Pesquisador Embrapa Soja, Londrina - PR, Fone: (43) 3371.6217, debiasi@cnpso.embrapa.br.

${ }^{4}$ Doutor, Professor Horista, Unisc, Santa Cruz do Sul - RS, Fone: (0XX51) 3717.7300, mmenegas @ unisc.br.

${ }^{5}$ Mestre, Doutorando Programa de Pós-Graduação em Engenharia Agrícola, UFSM, Santa Maria - RS, Fone: (0XX55) 3220. 8175, gustavoheller@hotmail.com.

Recebido pelo Conselho Editorial em: 2-6-2008
}

Aprovado pelo Conselho Editorial em: 25-2-2011 
desenvolvimento quanto à ergonomia e segurança inerentes a estes projetos (KHOURY JÚNIOR et al., 2004).

Atualmente, observam-se como tendência em projetos de máquinas agrícolas os avanços tecnológicos relacionados à ergonomia e segurança do operador, visando a incrementar as condições de trabalho, reduzir o nível de fadiga ao qual o operador está exposto, o risco de acidentes e aumentar a produtividade e a qualidade do trabalho (GRANDJEAN, 1998). Segundo SANTOS FILHO et al. (2004), o conforto do tratorista constitui um importante diferencial no aumento da produtividade nas operações agrícolas. FONTANA et al. (2004) citam a necessidade em considerar as características dos operadores e do trabalho que se realiza, visando à maior eficiência produtiva, maior grau de conforto e segurança na tarefa e obtendo melhoria das condições de trabalho. SANTOS et al. (2004) alertam para possíveis doenças que podem acometer os operadores que desempenham atividades agrícolas sob condições desfavoráveis. Não obstante, devem-se citar problemas relacionados à exposição a níveis de ruídos elevados, podendo gerar problemas de perda auditiva temporária, que pode evoluir para a perda auditiva induzida pelo ruído (PAIR), sendo um dano permanente, além de perturbações do estado de alerta e sono, conforme salientam MINETTE et al. (2007). Mesmo servindo como base para a melhoria das condições de trabalho e segurança, GIMENEZ \& MILAN (2007) relatam que apenas 24,4\% dos equipamentos utilizados em operações de pulverização, por exemplo, possuem cabinas.

SANTOS FILHO et al. (2004) salientam que estudos ligados à organização e à segurança do trabalho tendem a conceber sistemas de produção mais eficazes econômica, técnica e socialmente. Dentre os diversos fatores relacionados à ergonomia e à segurança em projetos de tratores agrícolas, destacam-se as condições de visibilidade. Nesse sentido, o campo visual é definido como sendo a área que pode ser visualizada pelo operador posicionado sobre o banco do trator.

Um bom campo visual é considerado essencial devido a diversos aspectos (MENEZEZ et al., 1985; GRANDJEAN, 1998). Os dois principais referem-se ao tempo de reação e à fadiga. Sob boas condições de visibilidade, o operador tem uma capacidade de reação mais rápida, o que colabora para a diminuição dos riscos de acidentes e, também, aumenta a eficiência do trabalho. É importante salientar ainda que este tempo de reação aumenta sensivelmente a partir do momento em que o operador se encontra fatigado em seu trabalho. Esta fadiga pode ser oriunda, dentre outras fontes, do próprio campo visual inadequado, o que leva o operador a movimentar-se constantemente para visualizar determinadas partes do conjunto trator-implemento, tornando-se mais exposto a acidentes e doenças ocupacionais.

O campo visual sofre a influência de diversos fatores. Conforme MENEZES et al. (1985), a altura do assento em relação à plataforma, o porte do trator, as características antropométricas do operador, presença, localização e ângulo em relação à direção de visão e o ângulo de inclinação da parte frontal do trator, entre outros, podem influenciar na definição do campo visual do operador. Assim, a inclusão de itens relacionados ao conforto e segurança, como estruturas de proteção contra o capotamento e as cabinas tendem a diminuir o campo visual (ROBIN, 1987). Neste contexto, o objetivo deste trabalho foi avaliar a alteração do campo visual de um trator ocasionada pela instalação de uma cabina.

\section{MATERIAL E MÉTODOS}

Este experimento foi executado no Setor de Mecanização Rural - UFSM, localizado no Câmpus da Universidade Federal de Santa Maria, Santa Maria - RS. Utilizou-se um trator Massey Ferguson modelo 5290 com tração 4x2. A cabina avaliada foi desenvolvida especificamente para tratores Massey Ferguson da série 5000. Nessa determinação, o trator estava equipado com pneus traseiros da marca Goodyear 18.4-34 R1, com diâmetro efetivo de $1.600 \mathrm{~mm}$ e pneus dianteiros da marca Firestone 9.00-16 com diâmetro efetivo de $800 \mathrm{~mm}$. Os pneus estavam com a pressão recomendada pelo fabricante do trator. Conforme a normalização, durante as medições, os rodados traseiros foram mantidos sem lastro. 
Os procedimentos utilizados para a determinação do campo visual foram baseados na norma ISO 5721 (1981) - Agricultural tractors - Operator's field of vision. Foi instalada uma lâmpada, montada em um suporte de altura regulável, posicionada $760 \mathrm{~mm}$ acima e $150 \mathrm{~mm}$ à frente do ponto de referência do assento, localizado conforme especifica a norma ISO 3462 (1979). O trator foi, então, colocado em um ambiente escurecido, a lâmpada foi acionada, projetando a sombra da máquina sobre o piso. As áreas obscurecidas foram demarcadas e medidas através de uma quadrícula. Foram determinadas a área de visibilidade nula (área total sombreada menos a área de projeção do trator), a área dos campos de visão estacionário dos olhos e obtido com o movimento da cabeça e, dentro de cada campo, as áreas de regiões obscurecidas pelos obstáculos.

Na determinação do efeito máscara, calculou-se a faixa de visão excluída do campo visual , o chamado efeito máscara, $(\mathrm{X})$, através da eq.(1):

$$
\mathrm{X}=[\mathrm{r}(\mathrm{b}-65) / \mathrm{a}]+65
$$

em que,

a - distância, em mm, entre o anteparo e a posição do olho, medido ao longo do raio que une a posição do olho, o centro do componente e do perímetro da visão (semi-círculo);

b - largura, em mm, do anteparo, medida horizontalmente e perpendicular ao raio visual;

$\mathrm{r}$ - raio do semicírculo de visão, determinado em $10.000 \mathrm{~mm}$, e

65 - distância interocular (entre olhos) de $65 \mathrm{~mm}$.

O delineamento experimental foi o inteiramente casualizado, com quatro repetições. Os tratamentos constaram da avaliação do campo visual do trator em duas situações: com cabina e sem cabina. As médias foram comparadas através do teste t de Student, a 1\% de probabilidade de erro.

\section{RESULTADOS E DISCUSSÃO}

Verifica-se que a presença da cabina influenciou negativamente no campo visual. Enquanto a área de visibilidade nula (área que o operador não consegue visualizar) foi de $58,69 \mathrm{~m}^{2}$ para o trator sem cabina, para o trator com cabina essa mesma área foi de $78,89 \mathrm{~m}^{2}$, ou seja, $34,42 \%$ superior. É importante salientar que a diferença entre as duas áreas de visibilidade nula foi estatisticamente significativa, o que foi comprovado através da aplicação do teste t de Student, a $1 \%$ de probabilidade de erro.

As melhores condições de visibilidade proporcionadas pelo trator sem cabina podem ainda ser comprovadas pela relação área do trator rebatida sobre o solo/área de visibilidade nula. Quanto maior for esta relação, melhores são as condições de visibilidade. Conforme se mostra na Tabela 1 , a referida relação foi de 0,075 para o trator sem cabina e de 0,057 para o trator com cabina.

TABELA 1. Médias para áreas do campo visual do trator com e sem cabina. Average to visual field areas of tractor with cabin and without cabin.

\begin{tabular}{|c|c|c|}
\hline Item $^{1}$ & Sem cabina $\left(\mathrm{m}^{2}\right)$ & Com cabina $\left(\mathrm{m}^{2}\right)$ \\
\hline $\mathrm{A}_{1}$ & 4,75 & 4,75 \\
\hline $\mathrm{A}_{2}$ & 63,43 & 83,70 \\
\hline $\mathrm{A}_{3}$ & 58,69 & 78,89 \\
\hline C.V. $(\%)$ & 0,9 & 0,87 \\
\hline $\mathrm{A}_{1} / \mathrm{A}_{2}$ & 0,075 & 0,057 \\
\hline
\end{tabular}

${ }^{1} \mathrm{~A}_{1}$ - área do trator rebatida sobre o solo; $\mathrm{A}_{2}$ - área da sombra produzida pelo trator sobre o chão; $\mathrm{A}_{3}$ - área de visibilidade nula ( $\mathrm{A}_{2}$ $\left.\mathrm{A}_{1}\right)$.

Uma representação esquemática das áreas de visibilidade nula para as duas situações comparadas neste trabalho é apresentada na Figura 1. Por esta Figura, pode-se inferir que o menor campo visual proporcionado pelo trator com cabina deveu-se à área de projeção dos acessórios e partes componentes da mesma, visto que a projeção do corpo do trator foi semelhante para os dois 
casos. Assim, fica comprovada a tendência indicada por MENEZEZ et al. (1985) e ROBIN (1987), em que a cabina, embora seja um elemento que aumenta as condições de conforto ao operador, contraditoriamente apresenta uma influência negativa sobre o campo visual.

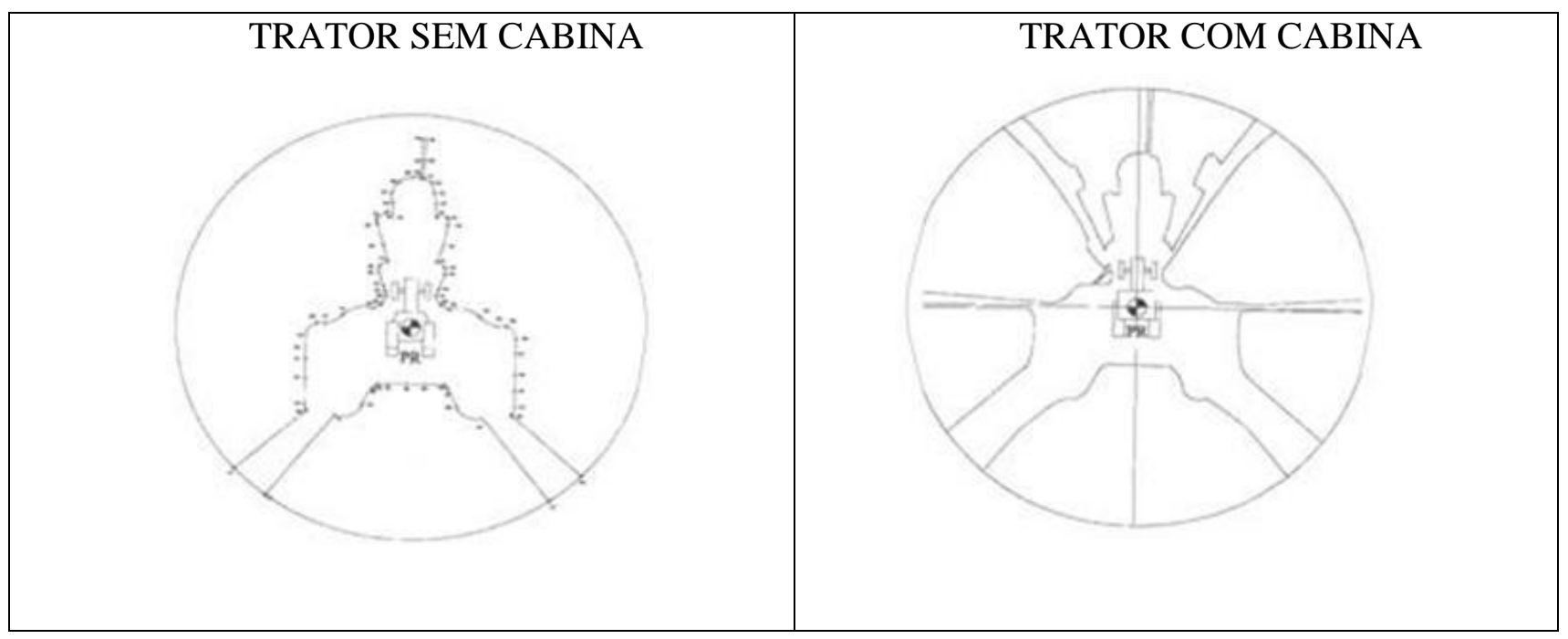

FIGURA 1. Área de visibilidade nula do trator, com e sem cabina. Null visibility area of tractor with cabin and without cabin.

Analisando-se os resultados, verifica-se também que a cabina, devido à diminuição do campo visual por ela provocado, tende a aumentar o risco de ocorrência de acidentes, pois essa redução ocasiona prejuízos substanciais à capacidade de percepção do operador.

Conforme exposto por diversos autores (MENEZEZ et al., 1985; ROBIN, 1987; GRANDJEAN, 1998), qualquer sinal de perigo que se apresente e fique localizado dentro das áreas de visibilidade nula, ocasionadas tanto pelo corpo do trator, como pela projeção de seus acessórios, não será visualizado pelo operador ou, pelo menos, será percebido somente após um determinado tempo. Isso significa, em termos práticos, um considerável incremento no tempo de reação do operador ao perigo, o que pode levar a um acidente.

Além disso, a redução no campo visual em função do uso de cabinas, detectada neste trabalho, ocasiona um aumento na fadiga do operador, pois este será obrigado a movimentar-se com maior frequência para visualizar determinadas regiões do conjunto trator e implemento.

Analisou-se também a influência da montagem da cabina sobre os diferentes campos visuais. $\mathrm{Na}$ Tabela 2, apresentam-se as áreas do campo visual estacionário dos olhos e obtido com o movimento da cabeça (respectivamente, campos visuais A, B e C).

Considerando-se os três campos visuais, a área sombreada pelos anteparos foi estatisticamente maior no trator com cabina, pelo teste de $t$ de Student a $1 \%$ de possibilidade de erro. No campo visual estacionário, a área encoberta pelos obstáculos foi de $1,75 \mathrm{~m}^{2}$ para o trator sem cabina e $2,62 \mathrm{~m}^{2}$ para o trator com cabina, sendo, portanto, 49,71\% superior no segundo caso. Para o trator sem cabina, a área encoberta foi devido a um único obstáculo (o escapamento), enquanto para o trator com cabina o sombreamento foi devido a três anteparos (escapamento, haste e limpador do para-brisa). A maior área encoberta, neste caso, foi proporcionada pelo escapamento. 
TABELA 2. Áreas dos campos de visibilidade do trator com e sem cabina $\left(\mathrm{m}^{2}\right)$. Area of visibility fields of tractor with cabin and without cabin $\left(\mathbf{m}^{2}\right)$.

\begin{tabular}{|c|c|c|c|c|}
\hline \multirow[t]{2}{*}{ Campo Visual $^{1}$} & \multirow[t]{2}{*}{ Área Total $^{2}$} & \multirow[t]{2}{*}{ Obstáculo $^{3}$} & \multicolumn{2}{|c|}{ Áreas Encobertas Pelos Obstáculos } \\
\hline & & & Sem cabina & Com cabina \\
\hline \multirow{4}{*}{ A } & \multirow{4}{*}{43,06} & 1 & 1,75 & 1,75 \\
\hline & & 2 e 3 & & 0,87 \\
\hline & & Total & 1,75 & 2,62 \\
\hline & & C.V. $(\%)$ & 1,02 & 1,19 \\
\hline \multirow{7}{*}{ B } & \multirow{7}{*}{103,05} & 1 & - & 0,87 \\
\hline & & 2 & - & 5,23 \\
\hline & & 3 & - & 7,82 \\
\hline & & 4 & - & 0,87 \\
\hline & & 5 & - & 5,230 \\
\hline & & Total & - & 20,02 \\
\hline & & C.V. (\%) & - & 0,065 \\
\hline \multirow{8}{*}{$\mathrm{C}$} & \multirow{8}{*}{111,12} & 1 & - & 7,82 \\
\hline & & 2 & - & 4,36 \\
\hline & & 3 & 8,68 & - \\
\hline & & 4 & - & 7,82 \\
\hline & & 5 & - & 4,36 \\
\hline & & 6 & 8,68 & - \\
\hline & & Total & 17,36 & 24,36 \\
\hline & & C.V. $(\%)$ & 0,40 & 0,74 \\
\hline
\end{tabular}

${ }^{\mathrm{T}} \mathrm{A}$ - campo visual estacionário $\left(-25^{0} \mathrm{a}+25^{0}\right)$; B - campo visual dos olhos $\left(-85^{0} \mathrm{a}+85^{0}\right)$; C - campo visual obtido com o movimento da cabeça $\left(-150^{0} \mathrm{a}+150^{0}\right) ;{ }^{2}$ área total medida considerando um raio do semicírculo de $10 \mathrm{~m} .{ }^{3}$ Ver Figura 2.

Já no que se refere ao campo visual B, pode-se notar que, excetuando-se o campo visual A que está contido no B, o trator sem cabina não apresentou obstáculos que pudessem resultar em áreas de visibilidade nula, enquanto o trator com cabina apresentou 5 obstáculos à visualização (haste do quebra-sol direita, suporte do para-brisa, espelho, haste do quebra-sol esquerdo e suporte do para-brisa + espelho esquerdo), os quais, em conjunto, produziram uma área sombreada de $20,2 \mathrm{~m}^{2}$.

Destes obstáculos, os espelhos foram os responsáveis pela maior interferência na visibilidade (sombreamento de $10 \mathrm{~m}^{2}$ ). Finalmente, o campo visual $\mathrm{C}$, que foi o mais reduzido pela interposição dos anteparos existentes no trator e/ou na cabina, apresentou uma área sombreada de $17,36 \mathrm{~m}^{2}$ para o trator sem cabina e $24,36 \mathrm{~m}^{2}$ para o trator com cabina, o que corresponde a uma diferença de $40,32 \%$ em relação ao primeiro caso. Os obstáculos que reduziram a visibilidade no trator sem cabina foram as estruturas de proteção, e para o trator com cabina foram as colunas centrais $\left(15,64 \mathrm{~m}^{2}\right.$ de área sombreada) e traseiras $\left(8,72 \mathrm{~m}^{2}\right.$ de sombreamento) da cabina. Da mesma forma, foi realizada a análise das áreas sombreadas por obstáculos (anteparos) existentes no trator e na cabina. Nas Figuras 2; 3 e 4, demonstram-se as áreas sombreadas pelos anteparos no campo visual A, B e C, respectivamente. 


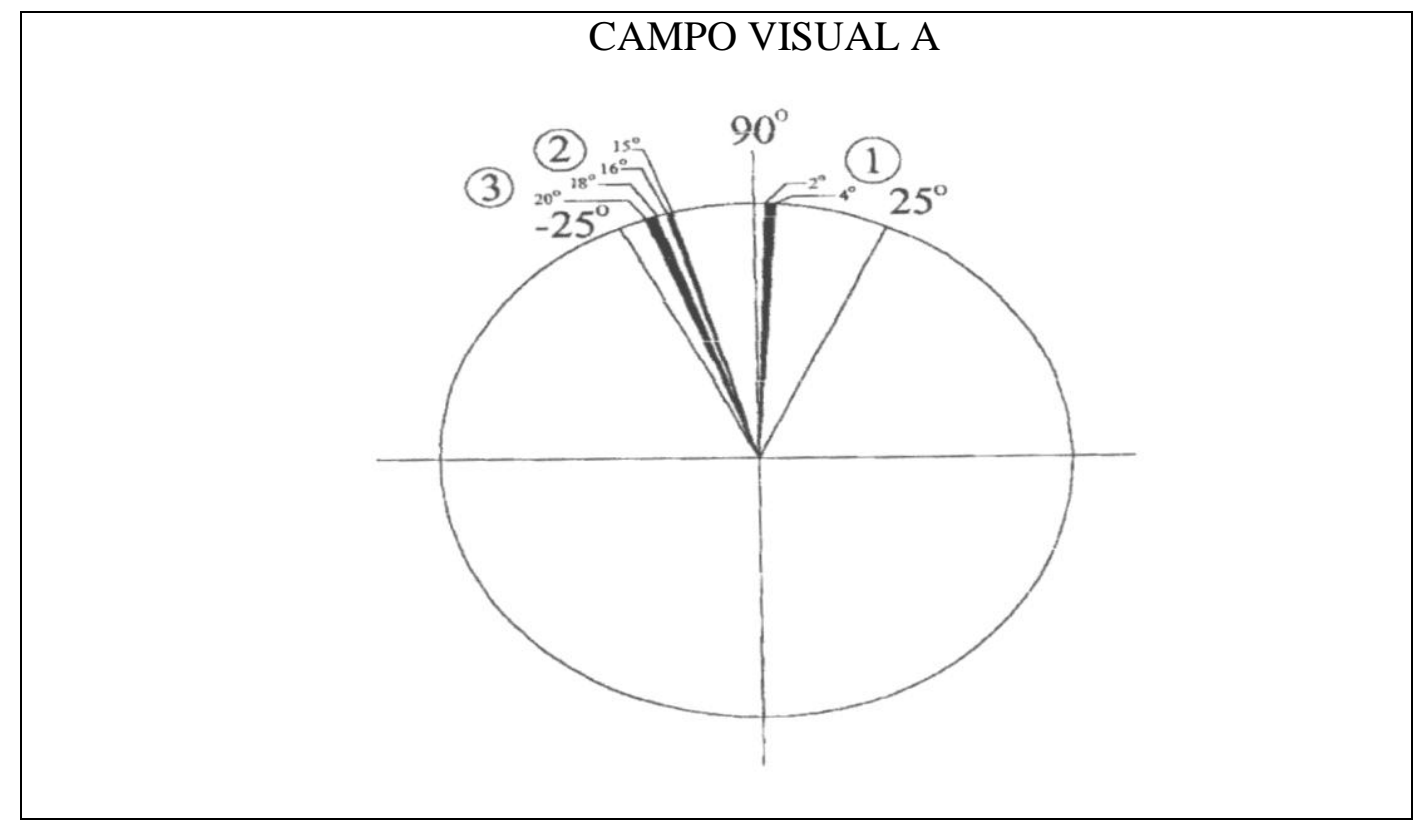

FIGURA 2. Campo de visão estacionário (A), para o trator com cabina. (1 - escapamento; 2 - haste do limpador de para-brisa; 3 - limpador do para-brisa). Static Visibility field (A), to tractor with cabin (1. Smoke tube; 2: Windshield wiper rod; 3: Windshield wiper).

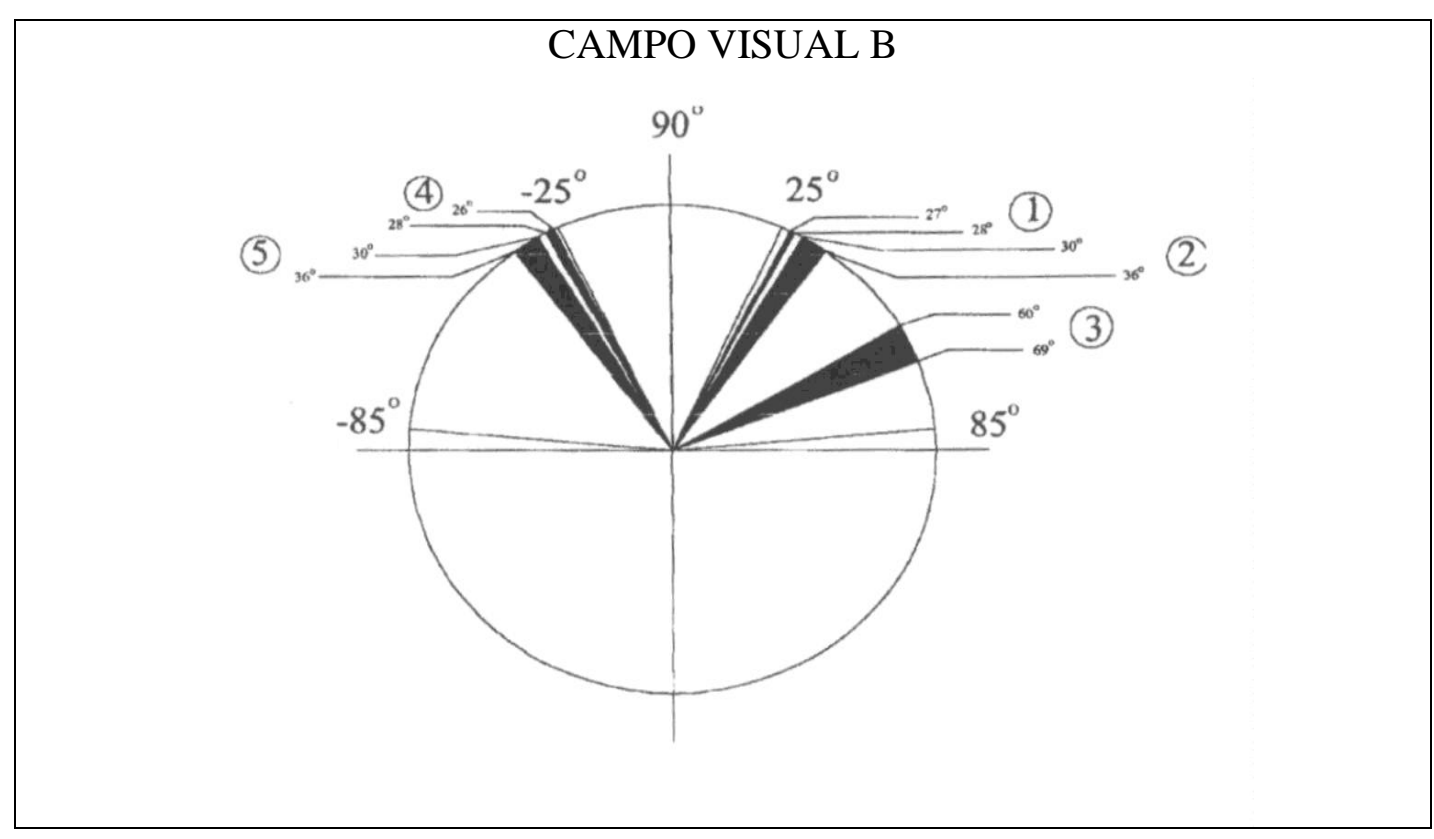

FIGURA 3. Campo de visão dos olhos (B), para o trator com cabina. 1 - haste do quebra-sol direito; 2 - suporte do para-brisa; 3 - espelho; 4 - haste do quebra-sol esquerdo; 5 - suporte do para-brisa e espelho esquerdo. . Eye visibility Field (B), to tractor with cabin. (1: Right side-visor rod; 2: Windshield support; 3: Mirror, 4: Left side-visor rod; 5: Windshield support and left mirror). 


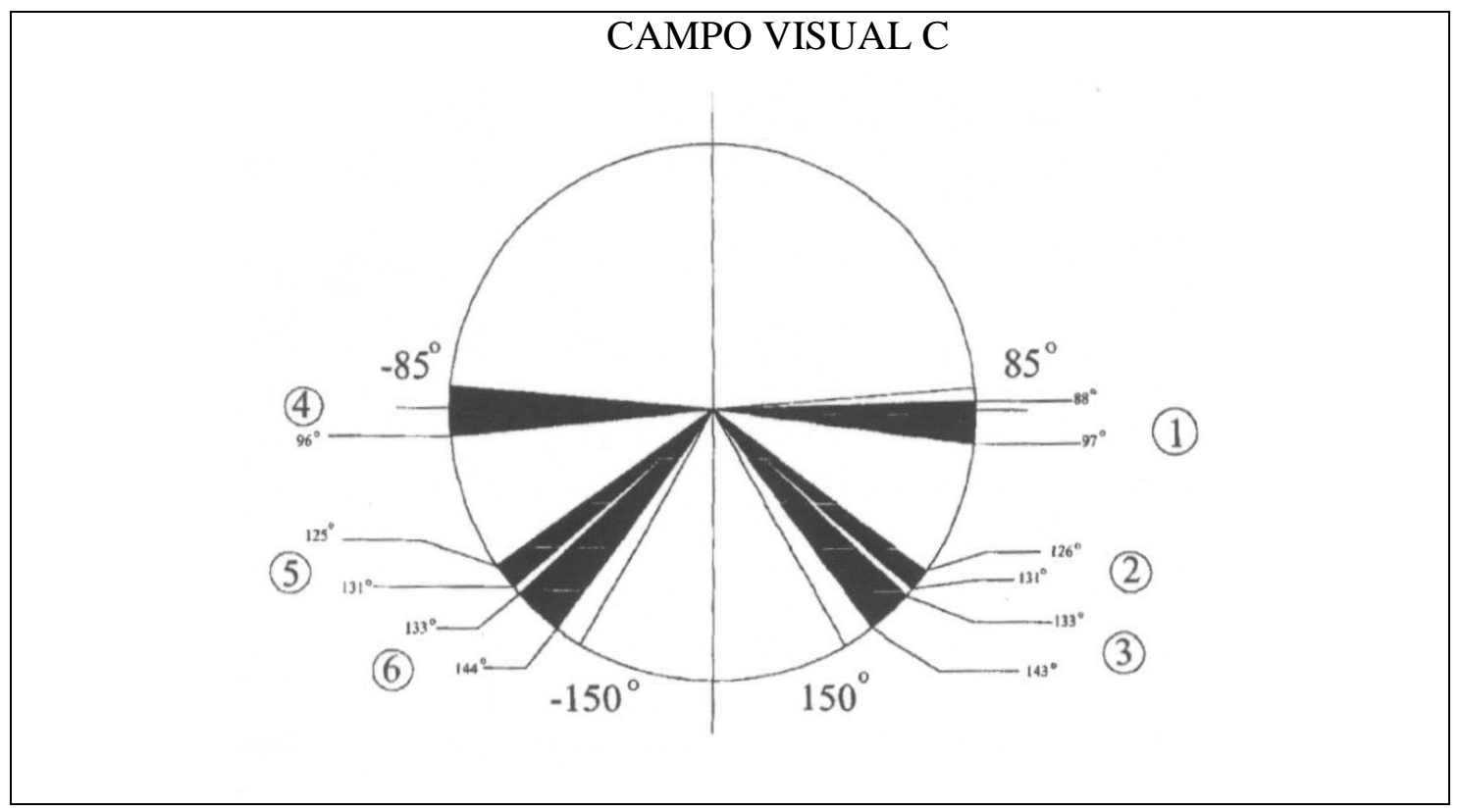

FIGURA 4. Campo de visão obtido com o movimento da cabeça $(C)$, para o trator com cabina. (1 e 4 - coluna central da cabina; 2 e 5 - coluna traseira da cabina; 3 e 6 - estrutura de proteção). Visibility Field obtained with the movement of the head (C), to tractor with cabin. ( 1 and 4; center structure of the cabin, 2 and 5: Rear structure of the cabin, 3 and 6: ROPS).

Apesar dos prejuízos advindos da redução do campo visual pela adição de cabinas, há de se considerar também a influência positiva que esta exerce sobre as condições ergonômicas do trator. Seguindo os estudos de ROBIN (1987) e GRANDJEAN (1998), as cabinas protegem o operador de condições ambientais desfavoráveis, como ruídos, temperaturas muito elevadas ou muito baixas, poeira, umidade, entre outros. Além disso, a presença de espelhos retrovisores no trator, quando equipado com cabina, melhora a visualização do trabalho executado pelo implemento ou equipamento conectado ao mesmo, diminuindo a necessidade do operador de girar em torno de seu próprio eixo.

Diante do que foi exposto anteriormente, é importante que o projeto das cabinas seja feito de forma a diminuir o máximo possível a existência de suportes que impeçam a visibilidade do operador. Também, deve-se levar em consideração a localização dos obstáculos, de maneira que, sempre quando for possível, os mesmos coincidam suas projeções.

\section{CONCLUSÕES}

Ao final, pôde-se constatar que a cabina influencia negativamente no campo visual, aumentando a área de visibilidade nula, comparativamente a um trator sem cabina, em aproximadamente $35 \%$. É necessário, portanto, melhorias, no projeto da cabina testada.

\section{AGRADECIMENTOS}

Às CABINAS REAL e à AGCO, pela cessão dos equipamentos, e aos Engenheiros Agrônomos Jorge Alex Willes e Otávio Dias da Costa Machado, pela colaboração na execução deste trabalho.

\section{REFERÊNCIAS}

FONTANA, G.; SILVA, R.P.; LOPES, A.; FURLANI, C.E.A. Avaliação de características ergonômicas no posto do operador em colhedoras combinadas. Engenharia Agrícola, Jaboticabal, v.24, n.3, p.684-694, set./dez. 2004. 
GIMENEZ, L.M.; MILAN, M. Diagnóstico da mecanização em uma região produtora de grãos. Engenharia Agrícola, Jaboticabal, v.27, n.1, p.210-219, jan./abr. 2007.

GRANDJEAN, E. Manual de ergonomia - adaptando o trabalho ao homem. 4.ed. Trad.: João Pedro Stein. Porto Alegre, 1998. p.199-234.

ISO. INTERNATIONAL ORGANIZATION FOR STANDARDIZATION. ISO 3462: Agricultural tractors and machinery - Seat Reference Point - Method of determination. Genève, 1979. 21 p.

ISO. INTERNATIONAL ORGANIZATION FOR STANDARDIZATION. ISO 5721: agricultural tractors- operator's field of vision. Genève, 1981. 4 p.

KHOURY JÚNIOR, J.K.; DIAS, G.P.; CORDEIRO, R.R.; SOUZA, C.M.A. Modelagem da estabilidade de tratores agrícolas de pneus. Pesquisa Agropecuária Brasileira, Brasília, v.39, n.5, 2004.

LIMA, J.S.S.; SOUZA, A.P. de; MACHADO, C.C.; PEZZOPANE, J.E.M.; AREAS, M.L. Estimativa das estabilidades longitudinal e transversal de tratores florestais utilizados na colheita de madeira. Revista Árvore, Jaboticabal, v.28, n.6, p.839-844, nov./dez. 2004.

MINETTE, L.J.; SILVA, E.P.; SOUZA, A.P.; SILVA, K.R. Avaliação dos níveis de ruído, luz e calor em máquinas de colheita florestal. Revista Brasileira de Engenharia Agrícola e Ambiental, Campina Grande, v.11 n.6, nov./dez. 2007.

MENEZEZ, J.F.; MAZIERO, J.V.G.; IAMASHITA, R.Y.; CORRÊA, I.M.; PASSARELLA NETO, A.; FENZ, E.; MILAN, M. Avaliação de características de visibilidade apresentadas por um grupo de tratores de rodas. Boletim Técnico IAC, Campinas. 1985. 17 p.

ROBIN, P. Segurança e ergonomia em maquinaria agrícola - tratores agrícolas. 1987. Monografia (Trabalho de Graduação em Agronomia) - Instituto de Pesquisas Tecnológicas do Estado de São Paulo, São Paulo, 1987.

SANTOS FILHO, P.F.; FERNANDES, H.C.; QUEIROZ, D.M.; SOUZA, A.P.; CAMILO, A.J. Utilização de um sistema de aquisição automática de dados para avaliação dos níveis de ruído de um trator agrícola de pneus. Revista Árvore, Viçosa-MG, v.28 n.3, p.381-386, maio/jun. 2004

SANTOS, J.E.G.; SANTOS FILHO, A.G.; BÓRMIO, M.F. Conforto térmico: uma avaliação em tratores agrícolas sem cabines. In: SIMPEP, 11., 2004, Bauru. Anais eletrônicos... 2004. 